\title{
Pendugaan Komponen Ragam, Heritabilitas dan Korelasi Klon-Klon Harapan Ubijalar Berkadar Betakaroten Tinggi
}

\section{The Estimation of Varian Component, Heritability, and Correlation of High Betacaroten Sweet Potato Promising Clones}

\author{
Wiwit Rahajeng $^{1 *}$ dan St. A. Rahayuningsih ${ }^{1}$ \\ ${ }^{1}$ Balai Penelitian Tanaman Aneka Kacang dan Umbi, Malang-Indonesia \\ Jln. Raya Kendalpayak Km 8, Kotak Pos 66. Malang, Indonesia \\ e-mail: wiwit.rahajeng@google.com
}

\begin{abstract}
High beta-carotene sweetpotato has an important role in the diversification and food security programs. Information on varian components, heritability, correlation and path analysis between quantitative characters with tuber yield are important for support the development of selection in sweetpotato varieties of high levels of beta carotene. The purpose of this study was to estimate the genetic variability, heritability, correlation, and path analysis on agronomic characters to determine the selection criteria in high beta-carotene sweetpotato clones. The research was conducted at Srengat, Blitar from April 2013 until August 2013. The materials used are 26 high beta carotene sweetpotato clones. Research arranged in a randomized block design (RBD) with three replications. The results showed all the characters have a broad sense heritability values were high but the number of tubers perplot. Extensive genetic variability shown by all the characters are observed. Based on heritability, genetic variability, correlation analysis, and path analysis, characters that can be used as selection criteria of high beta-carotene sweetpotato clones in this study is the weight of tubers per plot.
\end{abstract}

Keywords: sweet potato, variance components, heritability, correlation, path analysis

\section{INTISARI}

Ubijalar berkadar betakaroten tinggi mempunyai peranan penting dalam program diversifikasi dan ketahanan pangan. Informasi mengenai komponen ragam, heritabilitas, korelasi, dan path analisis diantara karakter kuantitatif dengan hasil umbi penting untuk mendukung program seleksi dalam pengembangan varietas ubijalar berkadar beta karoten tinggi. Tujuan dari penelitian ini adalah untuk mengestimasi ragam genetik, heritabilitas, korelasi, dan path analisis pada karakter agronomi untuk menentukan kriteria seleksi klon-klon ubijalar berkadar betakaroten tinggi. Penelitian dilaksanakan pada bulan April-Agustus 2013, di Srengat, Blitar. Bahan yang digunakan adalah 26 klon ubijalar berkadar beta karotin tinggi. Penelitian disusun dalam rancangan acak kelompok (RAK) dengan tiga ulangan. Hasil penelitian menunjukkan semua karakter mempunyai nilai heritabilitas arti luas yang tinggi kecuali jumlah umbi perplot. Ragam genetik yang luas ditunjukkan oleh semua karakter yang diamati. Berdasarkan nilai heritabilitas, ragam genetik, korelasi, dan path analisis karakter yang dapat digunakan sebagai kriteria seleksi klon-klon ubijalar berkadar betakaroten tinggi pada penelitian ini adalah bobot umbi per plot.

Kata kunci: ubijalar, komponen ragam, heritabilitas, korelasi, path analisis

\section{PENDAHULUAN}

Ubijalar merupakan pangan lokal untuk mendukung program diversifikasi pangan nasional dalam membangun kedaulatan pangan. Salah satu yang mempunyai peranan penting dalam program tersebut adalah ubijalar berdaging umbi oranye, yang menurut Wahibah et al. (2004) ubijalar berdaging umbi oranye merupakan salah satu sumber betakaroten atau provitamin A yang murah serta dapat digunakan untuk mengatasi kekurangan vitamin A yang mengakibatkan gangguan kesehatan mata atau xerophthalmia.

Pilihan varietas unggul ubijalar berkadar betakaroten tinggi masih terbatas, sampai saat ini di Indonesia hanya terdapat dua varietas unggul berkadar betakaroten tinggi yang sudah dilepas yaitu Beta-1 dan Beta-2, sehingga perakitan varietas unggul yang berkadar betakaroten tinggi 
masih perlu dilakukan. Kegiatan pemuliaan untuk merakit varietas unggul umumnya dilakukan melalui proses seleksi. Poehlman dan Sleeper (1995), menyatakan bahwa keragaman genetik sangat mempengaruhi keberhasilan suatu proses seleksi dalam program pemuliaan tanaman. Selain itu, nilai heritabilitas karakter-karakter yang akan dijadikan target seleksi juga perlu diketahui, karena menurut Rostini et al. (2006), seleksi akan berlangsung efektif pada karakter yang memiliki nilai heritabilitas tinggi. Adapun informasi lain yang perlu diketahui adalah korelasi dan sidik lintas antara berbagai karakter terhadap hasil (Ganefianti, 2006).

Berdasarkan beberapa penelitian pada ubijalar bobot per umbi, jumlah cabang, diameter umbi, dan panjang umbi berkorelasi positif dan nyata terhadap hasil umbi (Anshebo et al., 2004); bobot umbi per tanaman, indeks panen dan diameter umbi. berkorelasi positif dan nyata terhadap hasil umbi (Tsegaye et al., 2006); jumlah umbi berkorelasi positif dan nyata terhadap hasil umbi (Egbe et al. 2012). Dalam penelitian ini, pendugaan keragaman genetik, heritabilitas dan sidik lintas antara berbagai karakter terhadap hasil digunakan untuk menentukan kriteria seleksi.

Penelitian ini bertujuan menduga ragam genetik, heritabilitas, korelasi, dan path analisis pada karakter agronomi untuk menentukan kriteria seleksi klon-klon ubijalar berkadar betakaroten tinggi.

\section{BAHAN DAN METODE}

Penelitian dilaksanakan pada bulan April - Agustus 2013 di Srengat, Blitar. Bahan yang digunakan adalah 26 klon harapan ubijalar berkadar betakarotin tinggi. Penelitian disusun dalam rancangan acak kelompok (RAK) tiga ulangan dengan ukuran petak $2 \mathrm{~m} \times 5 \mathrm{~m}$. Panjang gulud $5 \mathrm{~m}$ dengan jarak tanam antar gulud $100 \mathrm{~cm}$ dan dalam gulud $25 \mathrm{~cm}$.

Pemupukan menggunakan dosis 300 $\mathrm{kg} / \mathrm{ha}$ pupuk Phonska dan $2 \mathrm{t} / \mathrm{ha}$ pupuk kandang. Penyiangan dilakukan tergantung pertumbuhan gulma, sekitar umur 4, 7 dan 10 minggu setelah tanam. Penurunan gulud dilakukan pada saat tanaman berumur satu bulan bersamaan dengan penyiangan I. Pembalikan batang dilakukan pada saat tanaman berumur 6, 9, dan 12 minggu setelah tanam, naik gulud dilakukan umur 2 bulan setelah tanam bersamaan dengan penyiangan kedua dan pemberian pupuk susulan. Pemberian air irigasi dilakukan sesuai kebutuhan untuk mencegah kekeringan atau kekurangan air. Pengendalian hama dan penyakit juga sesuai kebutuhan. Panen dilakukan pada umur 4-4,5 bulan setelah tanam. Variabel yang diamati meliputi: bobot tajuk segar perplot, jumlah umbi per plot, bobot umbi per plot, panjang umbi, diameter umbi, indeks panen, dan kadar bahan kering umbi, dan hasil umbi. Nilai rata-rata dari masing-masing karakter yang diteliti itu dihitung dan dianalisis ragamnya mengikuti prosedur yang dijelaskan oleh Gomez dan Gomez (1984) ragam fenotipik dan genotipik yang dihitung dengan metode yang disarankan oleh Burton dan Devane (1953). Kriteria keragaman genetik yang digunakan adalah seperti yang digunakan oleh Lestari et al. (2006). Analisis lintasan menggunakan metode yang dikemukakan oleh Singh dan Chaudhary (1977).

\section{HASIL DAN PEMBAHASAN}

Hasil analisa menunjukkan semua karakter memiliki nilai duga ragam genetik luas. Semua karakter juga memiliki nilai ragam fenotipe luas (Tabel 1). Beberapa penelitian pada ubijalar menunjukkan bahwa terdapat ragam genetik yang luas untuk panjang sulur, jumlah umbi, bobot umbi, panjang umbi, diameter umbi, indeks panen, kadar bahan kering umbi, dan hasil umbi (Wahyuni et al. 2004); jumlah umbi dan bobot umbi (Fajriani et al., 2012); dan panjang ruas dan bobot umbi per plot (Shaumi et al. 2012). Menurut Allard (1960), keragaman genetik yang luas merupakan syarat berlangsungnya proses seleksi yang efektif karena akan memberikan keleluasaan dalam proses pemilihan suatu genotipe. Karakter yang memiliki keragaman genetik yang luas akan memiliki keragaman fenotipe yang luas (Syukur et al., 2009).

Nilai duga heritabilitas pada 26 klon ubijalar yang diamati berkisar antara 49,6595,28\%. Hampir semua karakter menunjukkan nilai heritabilitas arti luas yang tinggi kecuali pada karakter jumlah umbi perplot yang menunjukkan nilai sedang (Tabel 2). Nilai duga heritabilitas suatu karakter perlu diketahui untuk menduga apakah karakter tersebut banyak dipengaruhi oleh faktor lingkungan atau genetik. Nilai heritabilitas yang tinggi menunjukkan bahwa pengaruh faktor genetik lebih besar terhadap penampilan fenotipe, dibandingkan pengaruh lingkungan. Nilai heritabilitas yang tinggi berperan dalam meningkatkan efektivitas seleksi (Syukur et al., 2009). 
Tabel 1. Nilai duga ragam genetik dan ragam fenotipe klon-klon harapan ubijalar

\begin{tabular}{lrrcrrl}
\hline Karakter & $\sigma^{2} \mathrm{G}$ & $2 \sigma \sigma^{2} \mathrm{G}$ & Kriteria & $\sigma^{2} \mathrm{P}$ & $2 \sigma \sigma^{2} \mathrm{P}$ & Kriteria \\
\hline bobot tajuk segar perplot (kg) & 20,72 & 13,51 & luas & 32,52 & 13,42 & luas \\
jumlah umbi per plot & 562,12 & 416,12 & luas & 1132,10 & 409,40 & luas \\
bobot umbi per plot (kg) & 27,56 & 17,38 & luas & 40,23 & 17,30 & luas \\
panjang umbi (cm) & 7,56 & 4,41 & luas & 9,16 & 4,41 & luas \\
diameter umbi (cm) & 1,57 & 0,95 & luas & 2,11 & 0,95 & luas \\
indeks panen (\%) & 3513,01 & 1944,24 & luas & 3688,63 & 1944,11 & luas \\
kadar bahan kering umbi (\%) & 9,83 & 5,51 & luas & 10,68 & 5,51 & luas \\
Hasil umbi (t/ha) & 31,33 & 17,33 & luas & 32,88 & 17,33 & luas \\
\hline
\end{tabular}

Keterangan: $\sigma{ }^{2} \mathrm{G}=$ ragam genetik, $\sigma \sigma{ }^{2} \mathrm{G}=$ standar deviasi ragam genetik, $\sigma{ }^{2} \mathrm{P}=$ ragam fenotipe, $\sigma \sigma{ }^{2} \mathrm{P}=$ standar deviasi ragam fenotipe

Nilai duga heritabilitas pada 26 klon ubijalar yang diamati berkisar antara 49,6595,28\%. Hampir semua karakter menunjukkan nilai heritabilitas arti luas yang tinggi kecuali pada karakter jumlah umbi perplot yang menunjukkan nilai sedang (Tabel 2). Nilai duga heritabilitas suatu karakter perlu diketahui untuk menduga apakah karakter tersebut banyak dipengaruhi oleh faktor lingkungan atau genetik. Nilai heritabilitas yang tinggi menunjukkan bahwa pengaruh faktor genetik lebih besar terhadap penampilan fenotipe, dibandingkan pengaruh lingkungan. Nilai heritabilitas yang tinggi berperan dalam meningkatkan efektivitas seleksi (Syukur et al., 2009).

Beberapa penelitian pada ubijalar menunjukkan bahwa nilai duga heritabilitas arti luas yang tinggi pada bobot umbi, karakter panjang umbi, diameter umbi, indeks panen, hasil umbi dan kadar bahan kering umbi (Wahyuni et al., 2004; Shaumi et al. 2012), jumlah cabang (Anshebo et al. 2004).

Tabel 2. Nilai duga heritabilitas klon-klon harapan ubijalar

\begin{tabular}{lcc}
\hline Karakter & Heritabilitas $(\%)$ & Kriteria \\
\hline bobot tajuk segar perplot $(\mathrm{kg})$ & 63,72 & Tinggi \\
jumlah umbi per plot & 49,65 & Sedang \\
bobot umbi per plot $(\mathrm{kg})$ & 68,50 & Tinggi \\
panjang umbi $(\mathrm{cm})$ & 82,54 & Tinggi \\
diameter umbi $(\mathrm{cm})$ & 74,37 & Tinggi \\
indeks panen $(\%)$ & 95,24 & Tinggi \\
kadar bahan kering umbi $(\%)$ & 92,04 & Tinggi \\
Hasil Umbi $(\mathrm{t} / \mathrm{ha})$ & 95,28 & Tinggi \\
\hline
\end{tabular}

Hasil analisis korelasi menunjukkan bahwa karakter yang berkorelasi positif dan sangat nyata dengan hasil umbi adalah jumlah umbi perplot, berat umbi perplot, diameter umbi, dan indeks panen. Sedangkan karakter bobot tajuk segar perplot, dan panjang umbi tidak berkorelasi terhadap hasil umbi (Tabel 3). Beberapa penelitian menunjukkan hal yang serupa. Hasil umbi memiliki korelasi positif dan nyata dengan bobot umbi per tanaman, indeks panen dan diameter umbi. (Tsegaye et al., 2006), dan jumlah umbi (Egbe et al. 2012). Untuk mempelajari pengaruh langsung dan tidak langsung antara karakter agronomi dengan hasil umbi maka dilakukan analisis lintas (sidik lintas).

Hasil analisis lintas menunjukkan bahwa karakter yang memiliki pengaruh total yang besar adalah bobot umbi perplot. Karakter yang memberikan pengaruh langsung yang cukup besar adalah bobot umbi perplot dengan koefisien lintas sebesar 1,00017 (Tabel 4). Dengan demikian, bobot umbi perplot dapat dijadikan kriteria seleksi. Selain itu, perlu juga dipelajari karakter yang mempunyai pengaruh tidak langsung. Karakter jumlah umbi, diameter umbi dan indeks panen memiliki pengaruh tidak langsung terhadap bobot buah per tanaman melalui bobot umbi. 
Tabel 3. Koefisien korelasi klon-klon harapan ubijalar

\begin{tabular}{lcrrrrrrr}
\hline Karakter & \multicolumn{1}{c}{ HU } & \multicolumn{1}{c}{ BT } & JU & BU & PU & DU & IP & KBK \\
\hline BT & $-0,307^{\text {tn }}$ & 1 & & & & & & \\
JU & $0,524^{* *}$ & $-0,078^{\text {tn }}$ & 1 & & & & & \\
BU & $1,000^{* *}$ & $-0,307^{\text {tn }}$ & $0,524^{* *}$ & 1 & & & & \\
PU & $-0,046^{\text {tn }}$ & $0,445^{*}$ & $0,005^{\text {tn }}$ & $-0,046^{\text {tn }}$ & 1 & & & \\
DU & $0,643^{* *}$ & $-0,543^{* *}$ & $-0,066^{\text {tn }}$ & $0,643^{* *}$ & $-0,596^{* *}$ & 1 & & \\
IP & $0,910^{* *}$ & $-0,632^{* *}$ & $0,462^{*}$ & $0,910^{* *}$ & $-0,223^{\text {tn }}$ & $0,715^{* *}$ & 1 & \\
KBK & $-0,430^{*}$ & $-0,042^{\text {tn }}$ & $-0,340^{\text {tn }}$ & $-0,430^{*}$ & $-0,323^{\text {tn }}$ & $-0,016^{\text {tn }}$ & $-0,352^{\text {tn }}$ & 1 \\
\hline
\end{tabular}

Keterangan: * = berkorelasi nyata pada taraf $5 \%, * *=$ berkorelasi sangat nyata pada taraf $1 \%$; HU= hasil umbi (t/ha), BT= bobot tajuk segar perplot $(\mathrm{kg}), \mathrm{JU}=$ jumlah umbi per plot, $\mathrm{BU}=$ bobot umbi per plot $(\mathrm{kg})$, panjang umbi $(\mathrm{cm})$, diameter umbi $(\mathrm{cm})$, indeks panen $(\%)$, dan $\mathrm{KBK}=\mathrm{kadar}$ bahan kering umbi $(\%)$

Penentuan karakter-karakter yang dapat dijadikan sebagai kriteria seleksi yang efektif dapat dilihat dari besarnya pengaruh langsung terhadap hasil, korelasi antara karakter dengan hasil, dan selisih dengan pengaruh langsung karakter tersebut terhadap hasil nilainya kurang dari 0.05. Jika ketiga hal tersebut dipenuhi, maka karakter tersebut sangat efektif sebagai kriteria seleksi untuk menduga hasil (Budiarti et al., 2004). Selain itu, informasi lain yang diperlukan dalam menentukan kriteria seleksi adalah keragaman genetik dan heritabilitas. Berdasarkan ketiga hal tersebut karakter yang dapat dijadikan kriteria seleksi pada penelitian ini adalah bobot umbi perplot.

Tabel 4. Pengaruh langsung dan tidak langsung beberapa karakter terhadap karakter hasil umbi klon-klon ubijalar

\begin{tabular}{|c|c|c|c|c|c|c|c|c|c|c|}
\hline \multirow[t]{2}{*}{ Karakter } & \multirow{2}{*}{$\begin{array}{l}\text { Pengaruh } \\
\text { langsung }\end{array}$} & \multicolumn{7}{|c|}{ Pengaruh tidak langsung } & \multirow{2}{*}{$\begin{array}{l}\text { Pengaruh } \\
\text { total }\end{array}$} & \multirow[t]{2}{*}{ Selisih } \\
\hline & & $\mathrm{BT}$ & $\mathrm{JU}$ & $\mathrm{BU}$ & $\mathrm{PU}$ & DU & IP & KBK & & \\
\hline$\overline{\mathrm{BT}}$ & $-0,000032$ & & 0,000003 & 0,000010 & $-0,000014$ & 0,000017 & 0,000020 & 0,000001 & 0.000005 & 0.000037 \\
\hline JU & $-0,000080$ & 0,000006 & & 0,000040 & $-0,000000$ & 0,000005 & $-0,000037$ & 0,000027 & -0.000039 & 0.000041 \\
\hline $\mathrm{BU}$ & 1,000170 & $-0,306979$ & 0,524279 & & $-0,046454$ & 0,643272 & 0,909692 & $-0,430310$ & 2.293670 & 1.293500 \\
\hline PU & $-0,000082$ & $-0,000037$ & $-0,000000$ & 0,000000 & & 0,000049 & 0,000018 & 0,000027 & -0.000025 & 0.000057 \\
\hline DU & $-0,000150$ & 0,000081 & 0,000010 & $-0,000100$ & 0,000089 & & $-0,000107$ & 0,000002 & -0.000175 & -0.000025 \\
\hline IP & $-0,000048$ & 0,000030 & $-0,000022$ & $-0,000040$ & 0,000011 & $-0,000034$ & & 0,000017 & -0.000086 & -0.000038 \\
\hline $\mathrm{KBK}$ & $-0,000004$ & 0,000000 & 0,000001 & 0,000000 & 0,000001 & 0,000000 & 0,000001 & & -0.000001 & 0.000003 \\
\hline
\end{tabular}

Keterangan: $\mathrm{HU}=$ hasil umbi $(\mathrm{t} / \mathrm{ha}), \mathrm{BT}=$ bobot tajuk segar perplot $(\mathrm{kg}), \mathrm{JU}=$ jumlah umbi per plot, $\mathrm{BU}=$ bobot umbi per plot $(\mathrm{kg})$, panjang umbi $(\mathrm{cm})$, diameter umbi $(\mathrm{cm})$, indeks panen $(\%)$, dan $\mathrm{KBK}=$ kadar bahan kering umbi $(\%)$

\section{KESIMPULAN}

1. Ragam genetik yang luas ditunjukkan oleh semua karakter yang diamati.

2. Semua karakter mempunyai nilai heritabilitas arti luas yang tinggi kecuali jumlah umbi perplot.

3. Karakter yang memberikan pengaruh langsung yang cukup besar adalah bobot umbi perplot

4. Berdasarkan nilai heritabilitas, ragam genetik, korelasi, dan path analisis karakter yang dapat digunakan sebagai kriteria seleksi klon-klon ubijalar berkadar betakaroten tinggi pada penelitian ini adalah bobot umbi per plot.

\section{DAFTAR PUSTAKA}

Allard, R.W. 1960. Pemuliaan Tanaman. Bina Aksara: Jakarta. $336 \mathrm{hlm}$.

Anshoebo, T., D. Veeraragavathatham., dan M. Kannan. 2004. Genetic Variability and Correlation Studies in Sweet potato (Ipomoea batatas Lam. L.). Madras Agric J. 91 (7-12): 420-424.

Budiarti, S.G., Y.R. Rizki., Y.W.E. Kusumo. 2004. Analisis koefisien lintas beberapa sifat pada plasma nutfah gandum (Triticum aestivum L.) koleksi Balitbiogen. Zuriat 15(1):31-40. 
Burton, G.W., and E.H. De Vane, 1953. Estimating heritability in tall fescue (Festuca arundinacea L.) from replicated clonal material. Agron. J., 45: 478-481.

Egbe, O. M., S. O. Afuape, and J. A. Idoko. 2012. Performance of Improved Sweet Potato (Ipomea batatas L.) Varieties in Makurdi, Southern Guinea Savanna of Nigeria. American Journal of Experimental Agriculture 2(4): 573-586, 2012

Fajriani, N., N.W.S. Suliartini., D. Boer., Suaib, dan T. Wijayanto. 2012. Variabilitas Genetik Sifat Agronomi Penting Beberapa Klon Ubi Jalar Lokal Yang dibudidayakan Di DesaDesa Pinggiran Kota Kendari. Berkala PENELITIAN AGRONOMI 1(1): 93-101.

Ganefianti, D.W., Yulian., A.N. Suprapti. 2006. Korelasi dan sidik lintas antara pertumbuhan, komponen hasil dan hasil dengan gugur buah pada tanaman cabai. Jurnal Akta Agrosia 9(1):1-6.

Gomez, K.A., and A.A. Gomez, 1984. Statistical Procedures for Agricultural Research. 2nd Edn., John Wiley and Sons Inc., New York, USA., ISBN: 13-9780471879312, Pages: 680.

Lestari, A.D., W. Dewi., W.A. Qosim., M. Rahardja., N. Rostini., R. Setiamihardja. 2006. Variabilitas genetik dan heritabilitas karakter komponen hasil dan hasil lima belas genotip cabai merah. Zuriat 17(1):94-102.

Poehlman, J. M., D. A. Sleeper. 1995. Breeding Field Crops. Iowa State University Press. USA.

Rostini N., E. Yuliani dan N. Hermiati, 2006. Heritabilitas, Kemampuan Genetik dan Korelasi Karakter Daun dengan Buah Muda,
Heritabilitas pada 21 Genotipe Nenas. Zuriat, 17(2): 114-121.

Shaumi, U., W. Chandria., B. Waluyo., dan A. Karuniawan. 2012. Potensi genetik ubijalar unggulan hasil pemuliaan tanaman berdasarkan karakter morfo-agronomi. Dalam A. Widjono, Hermanto, N. Nugrahaeni, A.A. Rahmianna, Suharsono, Fahrur Rozi, Erliana Ginting, A. Taufiq, A. Harsono, Y. Prayogo, E. Yusnawan, A. Winarto, dan K. Paramita Sari (eds.). Inovasi teknologi dan kajian ekonomi aneka kacang dan umbi mendukung empat sukses Kementerian Pertanian. Prosiding Seminar Hasil Penelitian Tanaman Aneka Kacang dan Umbi 2011.

Singh, R.K., and B.D. Chaudhary. 1977. Biometrical methods in quantitative genetic analysis. Kalyani Publ., New Delhi.

Syukur, M., S. Sujiprihati., R. Yunianti. 2009. Teknik Pemuliaan Tanaman. Departemen Agronomi dan Hortikultura, Fakultas Pertanian, Institut Pertanian Bogor. 300 hal.

Tsegaye, E., E. V. D. Sastry., and N. Dechassa. 2006. Correlation and Path Analysis in Sweet Potato and Their Implications for Clonal Selectin. Journal of Agronomy 5 (3): 391-395.

Wahibah N.N., A. Hartana., dan R. Megia. 2004. Analisis Genetika Ubijalar berdaging Umbi Jingga Melalui Persilangan dengan Ipomoea trifida Diploid. Hayati. 11 (4): 139-144

Wahyuni, T.S., R. Setiamihardja., N. Hermiati., dan K.H. Hendroatmodjo, 2004. Variabilitas Genetik, Heritabilitas dan Hubungan Antara Hasil Umbi Dengan Beberapa Karakter Kuantitatif dari 52 Genotip Ubijalar di Kendalpayak, Malang. Zuriat 15(2): 109-117. 